\title{
Tablets@university: The ownership and use of tablet devices by students
}

\author{
David Green, Essendran Naidoo, Caroline Olminkhof, Laurel Evelyn Dyson \\ University of Technology Sydney
}

\begin{abstract}
Tablet devices have made a dramatic impact in the computing industry, and have been widely adopted by consumers, including tertiary students. Published research surrounding the use of tablet computers in tertiary settings appears to be largely centred on the advantages of integrating tablets into university pedagogies. However, there appears to have been very little research into the current level of ownership and use amongst students beyond university-sponsored adoption programs. This paper sets out to provide baseline data on the level of ownership and the current usage of tablets by students at an Australian university. A survey of 200 undergraduate and postgraduate students and interviews with five students showed high tablet ownership and significant engagement with educational uses. The findings of this study have implications for the incorporation of tablets into university education.
\end{abstract}

\section{Introduction}

On January 27, 2010, Steve Jobs took to the stage at the Yerba Buena Centre in San Francisco to announce the iPad, a follow-up device in the iPod/iPhone range (Apple Inc., 2010). The iPad began a revolution in computing and spurred the release of an abundance of similar devices from other manufacturers trying to replicate its success. Four years after that event, 200 million iPads had been sold and, although initially slow to catch on, in 2013 the unit sales of Android tablets eclipsed those of the iPad for the first time (Telsyte, 2014). The Microsoft Surface tablet, released October 26, 2012, also represents a potentially strong future competitor in the tablet marketplace. Tablet devices such as these have dramatically changed the landscape for the computing industry, as well as the print and television industries. Historically, computing advances have originated in the business sector, in order to facilitate and improve productivity, but this is not the case with the tablet, which gained traction in the consumer market, putting pressure on business to adopt the technology.

Although much of the early research into tablet use in education focused on the Apple iPad, more recently sales of devices running on Android software have overtaken those of the Apple iPad. In the period spanning 2012 to 2013, sales of Android devices increased from 45.8\% market share to 61.9\% market share, whilst sales of Apple iPad devices fell from 52.8\% to 36\%. At the same time sales of the Microsoft product, a latecomer to the market, doubled from 1\% to 2.1\% (Gartner Inc., 2014). Complementing the rise in sales of Android devices has been a rise in the number of apps on offer in the Google Play store, where apps in the education section now number more than 140,000 (AppBrain, 2015), almost double the 75,000 in the Apple App Store (Apple Inc., 2015b).

There has been a huge adoption of tablet devices by the wider community in general, since the introduction of the iPad. At the same time, costs have fallen, which has further enhanced this phenomenon (Hargis et al., 2013). Part of the power of devices such as the tablet in educational settings is that students are already using these devices both inside and outside of universities (Johnson et al., 2012).

Tablets have been quickly adopted by tertiary students. The tablet's portability means that it can function as a substitute for paper notebooks as well as offering most of the functionality of a laptop (van Oostveen, Muirhead, \& Goodman, 2011). On the surface, most tablet devices have distinct disadvantages over a PC: they do not offer a mouse for precision tasks; have limited connections such as USB ports, optical disc drives, and audio/video sockets; and have only onscreen keyboards, which lack responsiveness for long periods of typing and occupy a substantial portion of the display space. However, since their debut, tablet devices have been seen by many as a perfect study companion for students, due in part to their innovative design and form. The current offerings from tablet manufacturers are now seen to offer many advantages over the traditional notepad and textbook for today's student and, featuring a touchscreen for control and viewing, provide an ideal format for consuming multimedia, digital books, and online content. These roughly A3-sized computing devices are lightweight and highly portable, have an unmistakable 
architecture and are readily transportable in a bag or backpack. Coupled with a battery life of approximately 10 hours, they are ideally suited to the needs of students. Software vendors have also embraced the educational possibilities offered by tablets, with over 50,000 educational apps currently available in the Google Play store and over 75,000 in the Apple App store (Apple Inc., 2015b; Google, 2014). The relatively low cost of tablet devices, their touch interface, and the abundance of available applications and accessories make these devices an engaging educational tool. The mass marketing of tablets has seen a collision of fashion, form, and functionality that has created an extremely popular consumer product, and anecdotal evidence would suggest this popularity is magnified in the tertiary education setting.

This paper firstly presents a review of the current literature along with the the research aims and methodology used. Following are the results of the survey and comments from interviews with students. The findings are then discussed. The major survey findings are that $62 \%$ of students surveyed owned a tablet, and a high proportion of these had purchased their tablet largely for their studies. Students used their tablets for a broad range of educational uses, as was confirmed by the interviews.

This study provides an insight into the level of ownership and the current uses of tablets by university students. The findings justify the greater incorporation of tablets into the university curriculum. The paper also contributes to our understanding of how academics might design new learning activities, based on the uses that students are already making of their devices.

\section{Literature review}

\section{Technology and new pedagogies in universities}

Tertiary educators are facing increasing pressure to adopt learning approaches that engage with today's technology. Due to the changing needs and experiences of both students and educators, education is currently undergoing a transformation away from the traditional pedagogy towards one that builds on new affordances offered by technology (Wakefield \& Smith, 2012). Indeed, the previous teaching model no longer functions to prepare graduates for life after university (Apple Inc., 2015a). Whilst in the past the lack of widespread adoption of technologies by students allowed educators to continue as they were, this is no longer the case (Johal, 2012). Indeed, the roles and expectations of teachers, as well as students, have evolved as a result of the increased use of mobile technologies in the educational environment (Wakefield \& Smith, 2012). The urgency of a transition to a more relevant model is increasing, as the adoption of tablet devices by students progresses at a much more rapid rate than the development of educational content (Hargis, Cavanaugh, Kamali, \& Soto, 2013). It is now up to universities and their faculty members to engage with the question of what new technologies may add value to the educational experience, and how they may do so (Guhr \& Gair, 2013).

Despite this, both the attitudes of teachers and the lack of professional training in educational uses of technology can be seen to have inhibited the adoption of new technologies into the sphere of tertiary education. Most professional development programs for faculty members have not effectively incorporated new technologies, and in many cases faculty have found it a challenge to keep up to date with current technological trends (Wakefield \& Smith, 2012). As educators already face significant demands on their time, they often find it problematic to schedule training programs to develop their technological expertise (Johal, 2012). Further, digital media literacy has not generally been expected for the academic professional, nor is it currently recognised as part of university training and development programs (Johnson, Adams, \& Cummins, 2012). Although many teachers have engaged with technology such as tablets at a personal level, they have not actually used it to enhance pedagogies, though this may come with time (Claburn, 2012).

In comparison with educators, students are generally well acquainted with technology; however, there is little evidence of any change in their attitudes in relation to learning. It would appear that a great deal must change both in the pedagogical approach of instructors and students' views of knowledge and learning before the potential of new technologies can be fulfilled in the academic environment (van Oostveen et al., 2011). It is unlikely that students have yet encountered teaching approaches that use tablets to meaningfully affect the educational process (van Oostveen et al., 2011). This reluctance on the 
part of instructors to engage with this technology, reinforced by students' learning experiences, results in a lack of student motivation to question whether tablet technology could be used in a more constructive way in their education (van Oostveen et al., 2011). In fact, where teaching and learning approaches conflict with a student's past experience, there is evidence that students resist this kind of change (van Oostveen et al., 2011). It can therefore be seen that for technology like tablets to be totally integrated into the learning process, student perceptions of university also need to be changed (Hargis et al., 2013).

As technology has evolved, and technology acceptance has grown, the situation has changed to the point that now many students currently entering tertiary education have come to expect that they will make use of their mobile devices as part of the educational process (Guhr \& Gair, 2013). This is also the case for a growing number of teachers, who are generally coming to rely on these technologies in order to organise and deliver material (Wakefield \& Smith, 2012). Ubiquitous computing is taken for granted, with all teachers and students constantly connected to a vast network of online environments, allowing them to engage in learning anywhere and at any time (van Oostveen et al., 2011). However, it is not clear that the current teaching methods employed by universities are as yet meeting these expectations.

\section{Advantages of using tablets in university education}

Tablets are offering new avenues for students to learn, provided that they are sufficiently integrated into the curriculum. They are feature-rich devices and thus ideal for digital textbooks and multimedia presentations, as well as field and laboratory work, where they are able to replace significantly more unwieldy and costly equipment (Hahn \& Bussell, 2012). Tablets have an affordance for note-taking and annotation, and permit both consumption and creation of content (Churchill, Fox, \& King, 2012). The use of tablets allows for a dynamic and interactive lecture experience for the student, leading to deeper learning (Manuguerra \& Petocz, 2011). Hahn and Bussell (2012) found that students were making use of the device's advanced features, including recording the material to review after class, which enhanced their learning.

The tablet's portability means that it can function as a substitute for paper notebooks as well as offering most of the functionality of a laptop (van Oostveen et al., 2011). Van Oostveen et al. (2011) found that students generally preferred to bring tablets to class as opposed to the laptops they had been using previously. Tablets provide universities with the benefits of mobile applications while offering the advantage of a larger screen than smartphones (Hood, 2014).

Although the use of tablets during class, particularly in larger classes, has been seen by some as having an adverse effect on student's learning, as they can be a distraction (Wakefield \& Smith, 2012), others note that tablet devices are generally far less disruptive than mobile and smartphones, making these technologies much more suitable to the learning environment (Johnson et al., 2012).

\section{Tablets challenge the traditional roles of student and teacher}

One of the key advantages offered by tablets is an increase in students' engagement with the learning process (Amelink, Scales, \& Tront, 2012). The ability to engage students' interest has been seen as an important reason for introducing these new devices, often accompanied by a new pedagogy. Institutions that have made changes in teaching methods specifically geared to tablet use have reported that the students themselves feel that they are more engaged with the material (Apple Inc., 2015a; Johnson et al., 2012). Manuguerra and Petocz (2011) assert that the levels of student interest and participation have markedly increased in such learning environments.

Further, integrating tablets into the curriculum allows students to take responsibility for their own learning experience. The focus shifts towards the student, allowing them to engage with the material being taught (Johnson et al., 2012), to work at their own level, and to undertake their own research and independent thinking outside of the confines of classroom (Hargis et al., 2013). Students supplement the knowledge imparted by the teacher with information from the Internet that they have found on their own (Wakefield \& Smith, 2012). Indeed, in this new pedagogy, the role of the student is much more active: it is less about learning the facts and more targeted towards using information in challenging and practical ways (Apple Inc., 2015a; Johnson et al., 2012). With these less formal teaching methods, academics can provide students with feedback and impart their expectations to those students unused to this pedagogy 
(Wakefield \& Smith, 2012). The role of the teacher evolves, from that of an instructor towards a more facilitating role, developing the students' ideas about the material rather than merely imparting knowledge (Hargis et al., 2013).

Integrating tablets in the learning environment can also increase collaboration between the students in the class. Tablets are used by students as devices for both academic and social functions, and can even act as a conversation starter amongst first-year students who have been issued with a device (Apple Inc., 2015a). There is also evidence of increased collaboration between students and faculty: for example, in one study students using tablets looked at emails from their instructors more frequently (Apple Inc., 2015a). Thus, tablets can be seen as assisting with overcoming the challenge of sharing information between students and teachers (Hargis et al., 2013). Further, students came to believe that the university cared about how they were learning, as they had taken action to make their learning environment more flexible (Apple Inc., 2015a).

\section{The changing make-up of brands of tablet devices}

Although much of the early research into tablet use in education focused on the Apple iPad, more recently sales of devices running on Android software have overtaken those of the Apple iPad. In the period spanning 2012 to 2013, sales of Android devices increased from 45.8\% market share to 61.9\% market share, whilst sales of Apple iPad devices fell from 52.8\% to 36\%. At the same time, sales of the Microsoft product, a latecomer to the market, doubled from 1\% to 2.1\% (Gartner Inc., 2014). Complementing the rise in sales of Android devices, has been a rise in the number of apps available from the Google Play store, where apps in the education section now number more than 50,000 (Google, 2014), though still short of the 75,000 in the Apple App Store (Apple Inc., 2015b).

\section{Research aims}

Given that the majority of research to date centred around either the advantages that tablet devices offer education or evaluating the provision of tablet devices to students, it was felt that there was a need to examine how many students had already purchased these devices for themselves, and how they were currently using them to assist in their studies. As such the research was focused on the following areas:

- How many students currently own tablet devices, and what kind?

- What kinds of things do they use them for in terms of their studies?

- What kinds of things do they use them for outside of their studies?

In this way, this research aims to provide a picture of the current usage of tablet devices by tertiary students in a university that has not yet undertaken any systematic implementation of tablet devices.

\section{Methodology}

The research was conducted at an Australian metropolitan university in the autumn semester of 2014, and consisted of a survey in addition to interviews with selected participants.

\section{Student surveys}

In order to collect data from a reasonable number and wide variety of students, a survey was conducted. Initial questions collected simple demographic data on participants including whether they were undergraduate or postgraduate students; full-time or part-time; the discipline they were pursuing; their age bracket; whether they were enrolled as a local or international student; and the approximate number of hours of paid employment that they undertook each week. Opt-out answers were provided for more sensitive demographic questions, such as employment. Students were asked to check or tick the most appropriate answer from a list of alternatives: for example, the question "On average, how many hours of paid employment do you do each week?” could be answered by checking "None - I do not do any paid work”; “1-15”; “16-30”; “31+”; or "Prefer not to say”. 
The principal questions regarding the ownership and use of tablet devices began with a yes/no question "Do you own a tablet device?" If students answered "Yes", they were asked to answer questions about tablets in their studies: ("What brand is your tablet?", "Do you bring your tablet with you to university? [always, usually, sometimes, rarely or never]", "When deciding to purchase your tablet, how much consideration did you give to its potential to assist you in your studies?", "For your studies, which of the following [functions] do you use your tablet for?") and a question about tablet use outside university ("Outside of your studies, what do you use your tablet for?"). If students answered "No" to the question about tablet ownership, they were directed to two questions ("What are your primary reasons for not owning a tablet?" and "What technology do you bring with you to university?". Like the demographic questions, students were asked to check the most appropriate answer from a list of alternatives, generally with an option "Other (Please specify)". Where more than one answer was possible, for example, for uses of the technology, reasons for not owning a tablet or other technologies brought to university, checkboxes were used, while for questions with only one possible answer, for example, age group or the frequency of bringing the tablet to university, option or radio buttons were used.

The questions were pilot tested by a group of four students from the university and one tester with market research experience. Responses from this pilot group were not included in the final survey. Using their feedback, the survey structure and questions were refined before release to the target group. The final survey consisted of 20 questions for students who owned tablet devices and 10 questions for those who did not. The survey was designed and released using the SurveyGizmo web platform, and included an information page and contact details should they have any questions about the survey and how the results were being used. Some students (55.5\%) completed the survey online, accessible from a student portal, while others (44.5\%) completed the survey on paper, recruited in common areas of various faculty buildings on campus and in an information technology (IT) class. Responses collected on paper were entered into the SurveyGizmo platform to assist data analysis. Survey data was analysed by first assessing the responses in terms of the demographic information collected. In some instances, such as faculty, groups were combined to result in groupings of roughly even number. These demographic groups were then used to compare the responses received to questions relating to tablet ownership and use.

There were a total of 200 completed surveys, with a response rate of 52\%. Respondents were asked to provide an email address if they wished to participate in a random prize draw for three \$20 app store gift cards, as an incentive to completing the survey, or if they were willing to be contacted for further interviews. However, these email addresses were not used to identify individual responses beyond the purposes for which they had been collected, thus the survey responses were anonymous.

\section{Student interviews}

In order to gain a deeper understanding into tablet ownership, as well as how and why students used their devices for their studies, five interviews were conducted. The students interviewed included three identified as super users (students who owned and reported multiple and varied uses of their tablets), as well as two students who did not own tablets. Four interviews were conducted in person and one via Skype; all students were provided with an information sheet regarding the research, signed a consent form indicating their willingness to take part, and for audio of the interviews to be recorded. All interviews were semi-structured, that this, a list of general topics was devised, but interviews were allowed to evolve based around student responses.

\section{Survey results}

As can be seen in Table 1 below, the 200 survey responses were grouped into demographic categories for analysis. They reveal that a wide variety of students were captured, including postgraduates, undergraduates, local/international. We surveyed IT versus non-IT students in order to provide a balance between students who might be considered technologically advanced and those who might have less interest in technology. Non-IT students surveyed included those studying in the faculties of Arts and Social Sciences; Design, Architecture and Building; Health; Law; Science; as well as the Business School. 
Table 1

Survey demographics

\begin{tabular}{|c|c|c|c|c|}
\hline & & $\begin{array}{l}\text { Percentage of } \\
\text { students }\end{array}$ & $\begin{array}{l}\text { Number of } \\
\text { students }\end{array}$ & \\
\hline \multirow[t]{2}{*}{ Degree type } & Postgraduate & $61.50 \%$ & 123 & \\
\hline & Undergraduate & $38.50 \%$ & 77 & Total $=200$ \\
\hline \multirow[t]{2}{*}{ Faculty } & $\begin{array}{l}\text { Information } \\
\text { technology (IT) }\end{array}$ & $52.00 \%$ & 104 & \\
\hline & Other disciplines & $48.00 \%$ & 96 & Total $=200$ \\
\hline \multirow[t]{2}{*}{ Background } & International & $44.67 \%$ & 88 & \\
\hline & Local & $55.33 \%$ & 109 & Total $=197$ \\
\hline \multirow[t]{2}{*}{ Age } & Under 25 & $53.50 \%$ & 107 & \\
\hline & 25 and over & $46.50 \%$ & 93 & Total $=200$ \\
\hline \multirow[t]{3}{*}{ Employment } & None & $37.89 \%$ & 72 & \\
\hline & $\begin{array}{l}\text { Part time (under } \\
31 \text { hours) }\end{array}$ & $47.89 \%$ & 91 & \\
\hline & $\begin{array}{l}\text { Full time (31 } \\
\text { hours or more) }\end{array}$ & $14.21 \%$ & 27 & Total $=190$ \\
\hline
\end{tabular}

\section{Tablet ownership}

As can be seen in Figure 1 below, 62\% (124 students) reported owning a tablet device at the time.

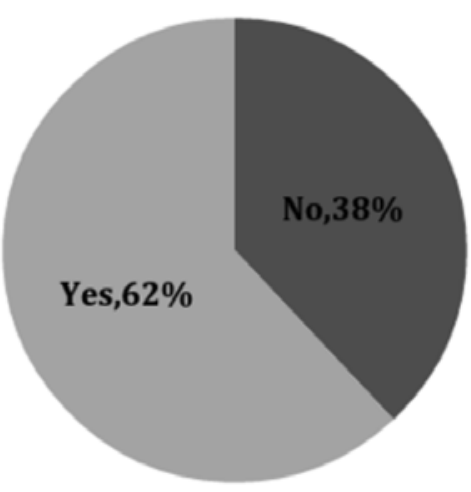

Figure1. Tablet ownership amongst survey respondents

Postgraduate respondents had a higher incidence of tablet ownership (66.67\%; undergraduates: 54.55\%), but in both groups more than half the students surveyed owned the devices. This trend continued when the age of students was assessed, with $67.74 \%$ of respondents aged 25 or older reportedly owning a tablet, compared to $57.01 \%$ of students under the age of 25 .

IT students also reported a higher ownership percentage than students in other faculties overall (65.38\%; and non-IT students: 58.33\%); however, when only postgraduate students were assessed, this trend reversed, with 9.95\% less IT postgraduates owning tablets than their non-IT counterparts (IT: 65.05\%; other: $75 \%$ ), and therefore the relationship between faculty and tablet ownership is unclear from our results.

We further found that international students and those who worked full time were more likely to own tablet devices. International student respondents reported a $67.05 \%$ uptake rate, compared to $58.72 \%$ of local students. Also, $70.37 \%$ of students surveyed who worked an average of 31 or more hours per week owned tablets, whilst students who reported working part-time (between 1 and 30 hours per week) had a lower uptake rate than students who did not work at all (58.24\% of part-time workers, and $62.5 \%$ of nonworking students). 


\section{Representation of tablet brands}

Students were also asked what brand of tablet they owned. As can be seen in Figure 2 below, students surveyed were much more likely to own Apple tablets than other models, with $67.74 \%$ of respondents owning devices of this brand. Postgraduate students were slightly more likely to own Apple devices (69.51\%; undergraduates: 64.19\%), as were non-IT students (69.64\%; IT: 66.18\%). This trend was exacerbated within the postgraduate student group, with $80 \%$ of non-IT postgraduate students owning Apple tablets (IT: 67.17\%). International students were also 12.08\% more likely to own Apple devices than their local counterparts (international: 74.58\%; local: 62.50\%). Students aged 25 or over were also much more likely to own non-Apple devices (41.27\%; under 25: 22.95\%), as were those working 31 hours or more a week (52.63\%, compared to $29.87 \%$ of part-time or non-working students).

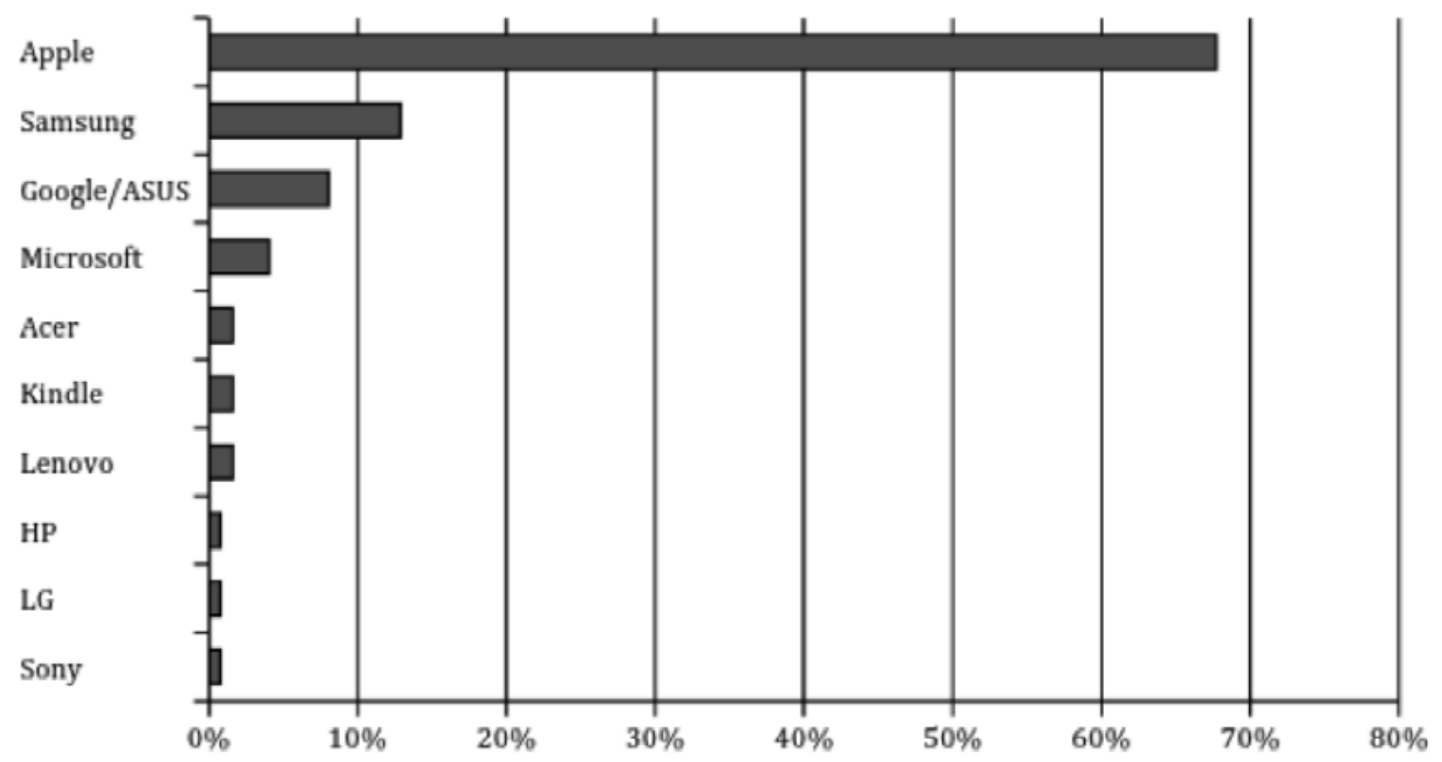

Figure 2. Tablet brands owned by students

\section{Tablets on campus}

Tablet-owning survey respondents were further asked how frequently they brought their tablets to university, the results and scale of which can be seen in Table 2 below. Exactly $50 \%$ of these students reported that they always or usually brought their tablets to campus, whilst only $25 \%$ reported that they rarely or never brought their tablets. There was very little variance in the percentage of students that always brought their tablets to university in any of our statistical groups (age, faculty, degree type, or background), with the exception of students who worked full time, who were $11.88 \%$ more likely to report this category than the mean.

Table 2

Frequency of students bringing tablets to university

\begin{tabular}{lcc}
\hline & Percentage of students & Number of students \\
\hline Always & $35.48 \%$ & 44 \\
Usually & $14.52 \%$ & 18 \\
Sometimes & $25.00 \%$ & 31 \\
Rarely & $16.94 \%$ & 21 \\
Never & $8.06 \%$ & 10 \\
\hline
\end{tabular}

\section{Importance of university studies in students' decision to purchase a tablet}

These participants were also asked what, if any, influence their studies had in their decision to purchase their tablet devices. Results can be seen in Table 3 below. Responses indicate that this was a factor in the majority of students' decision to purchase a tablet, with only $33.87 \%$ of students reporting that university 
had little or no influence in this decision. However, very few students purchased their tablets for this reason alone (13.71\%), with very little variance between demographic groups.

Table 3

Influence of studies in student tablet purchase

\begin{tabular}{lcc} 
& Percentage of students & Number of students \\
\hline None at all & $15.32 \%$ & 19 \\
A little & $18.55 \%$ & 23 \\
Some & $28.23 \%$ & 35 \\
A lot & $24.19 \%$ & 30 \\
Solely for studies & $13.71 \%$ & 17 \\
\hline
\end{tabular}

We also found no obvious correlation between students who reported bringing their tablets to university and the importance their studies had in their purchasing decision. Only 35.48\% of students who reported that their studies heavily influenced their purchase or those who purchased them solely for their studies reported that they usually or always brought them to campus. Similarly, of those students who reported that their studies had little or no influence in their decision to purchase the devices, only $16.93 \%$ rarely or never brought them to university.

\section{Students' use of tablets for their studies}

One of our main survey aims was to find out how students used their tablets for their studies, with results from this question shown in Figure 3 below. The most popular functions in this context were email (71.77\%), using the Internet (70.16\%), accessing course documents (62.9\%), reading required texts (60.8\%), and social media (56.45\%), with more than half of tablet-owning students using their devices for each of these functions. Less, but still reasonably popular were following along with lectures (47.58\%), taking notes (36.29\%), studying for exams (35.48\%), and annotating course materials (29.84\%). The least popular usages were taking photos or videos (25.81\%), completing assignments (14.52\%), and drawing pictures or diagrams (12.10\%).

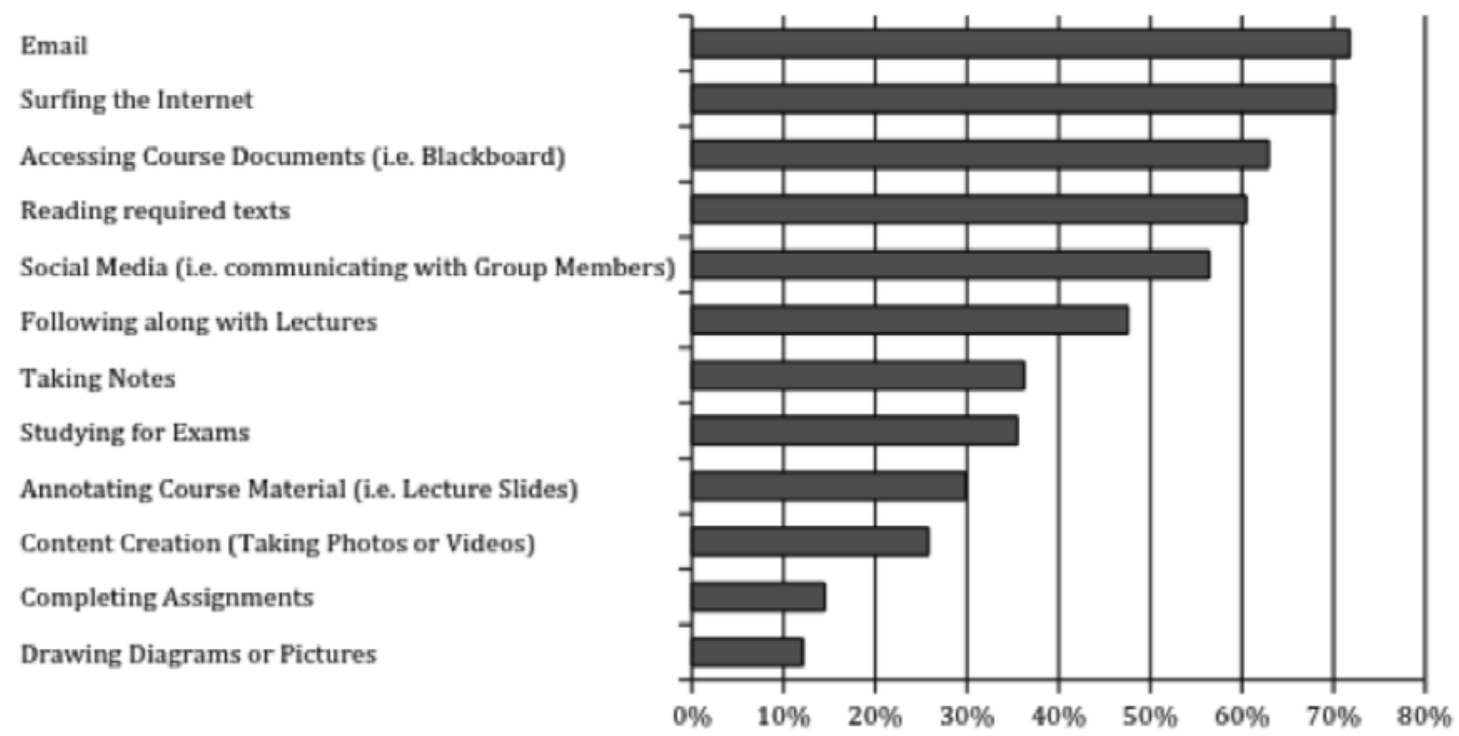

Figure 3. Students' usage of their tablets for their studies

Students aged under 25 were marginally more likely to report using their tablets for their studies than their older counterparts (average across all uses amongst students under 25: 45.36\%; 25 or over: 41.93\%). Whilst IT students were less likely to report using their tablets for their studies than those studying in other faculties (average across all uses amongst IT students: 40.07\%, other faculties: 47.92\%); a trend that was exacerbated when analysing only postgraduate students (average across all uses amongst IT postgraduates: $39.80 \%$; non-IT postgraduates: 51.67\%). Postgraduate students overall were also less 
likely to report using their tablets for any of these usages (average across all uses for postgraduates: 41.97\%; undergraduates: 46.83\%).

Whilst following along with lectures, taking notes, and annotating course materials were less popular, all three of these uses represent activities that would normally take place during class; $66.13 \%$ of tablet owners reported that the use their tablet in one or more of these ways. Fewer than $30 \%$ of respondents (29.84\%) indicated that they used their tablets for any of the traditional content-creation purposes (including taking photos and videos, drawing diagrams or pictures, and completing assignments), indicating that the devices are still mainly used for content consumption in the university environment.

Only $8.87 \%$ of tablet-owning respondents reported that they never used their tablets for their studies, which closely correlated to the percentage of students who did not bring their tablets to university (8.06\%).

\section{Students' use of tablets outside of their studies}

Complementing the above, students were also asked about how they used their tablets outside of their studies. The results are shown in Figure 4 below. The most popular functions in this context were surfing the Internet (86.29\%), followed by social media (77.42\%), email (75\%), and watching videos (72.58\%), with more than $70 \%$ of students reporting each of these uses. This was followed by playing games (58.06\%), reading e-books, magazines, or newspapers (54.84\%), and listening to music (51.61\%), with more than half of the respondents reporting these uses. Taking photos was the highest of the traditional content-creation uses with $44.35 \%$, followed by work (22.58\%), recording video (21.77\%), and sketching or drawing $(0.81 \%)$.

Surfing the Internet
Social Media
Email
Watching Video
Playing Games
Reading (E-books, Magazines, or Newspapers)
Taktening to Music
Work
Recording Video
Sketching/Drawing

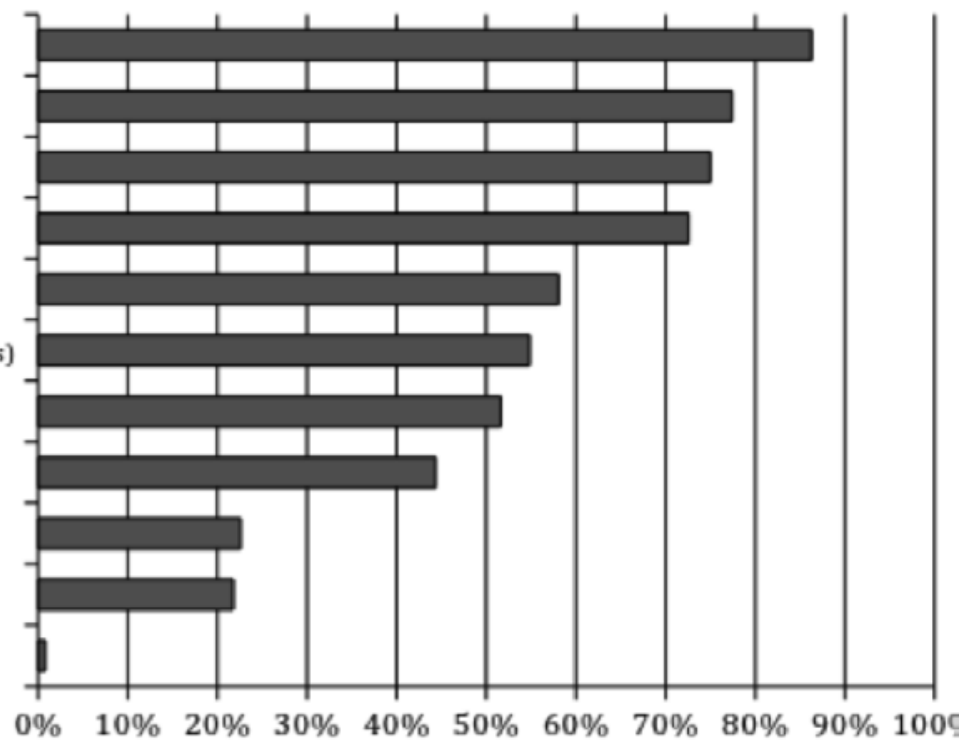

Figure 4. Student usage of their tablets outside of their studies

Once again, students aged under 25 were slightly more likely to report using their tablets for the purposes listed than reports by their older counterparts (average across all uses amongst students under 25: 52.91\%; 25 or over: 49.93\%). Postgraduate students were also still less likely to report using their tablets for any of these usages (average across all uses for postgraduates: $49.11 \%$; undergraduates: 55.84\%).

IT students were also less likely to report using their tablets outside of their studies than students in other faculties (average across all uses amongst IT students: $47.99 \%$; other faculties: $55.52 \%$ ), this difference dropped slightly when analysing only postgraduate students (average across all uses amongst IT postgraduates: $48.17 \%$; non-IT postgraduates: $53.33 \%$ ). 


\section{Non-tablet owners}

In terms of the 76 students who did not own a tablet at the time of the study, as can be seen in Table 4 below, 34.21\% of these students indicated that they intend to purchase a tablet device in the future. Both postgraduate students (46.34\%), and IT students (52.78\%) were more likely to indicate this intention (undergraduate: 20\%; non-IT: 17.5\%). International students were also much more likely to report their intention of purchasing a tablet (51.72\%; local: 22.22\%).

Table 4

Student reasons for not owning a tablet

\begin{tabular}{lcc}
\hline & Percentage of students & Number of students \\
\hline Like using laptop & $48.68 \%$ & 37 \\
Don't offer any extra functionalit: & $36.84 \%$ & 28 \\
Planning on buying one in the fut & $34.21 \%$ & 26 \\
Like using smartphone & $30.26 \%$ & 23 \\
Too expensive/cannot afford one & $18.42 \%$ & 14 \\
Don't like them & $5.26 \%$ & 4 \\
\hline
\end{tabular}

Aside from this, the most popular reasons students reported for not owning a tablet were that they liked using their laptops (48.68\%), that the devices do not offer any additional functionality (36.84\%), or that they liked using their smartphones (30.26\%). Only 18.42\% of students identified that the devices were too expensive or that they could not afford to buy one. Very few students reported that they did not like the devices $(5.26 \%)$.

We further asked what kinds of technology, if any, they brought with them to university. As can be seen in Figure 5 below, most of these students brought both their smartphone (89.47\%) and laptop (73.68\%) with them to university. None of the students surveyed reported that they brought neither device with them.

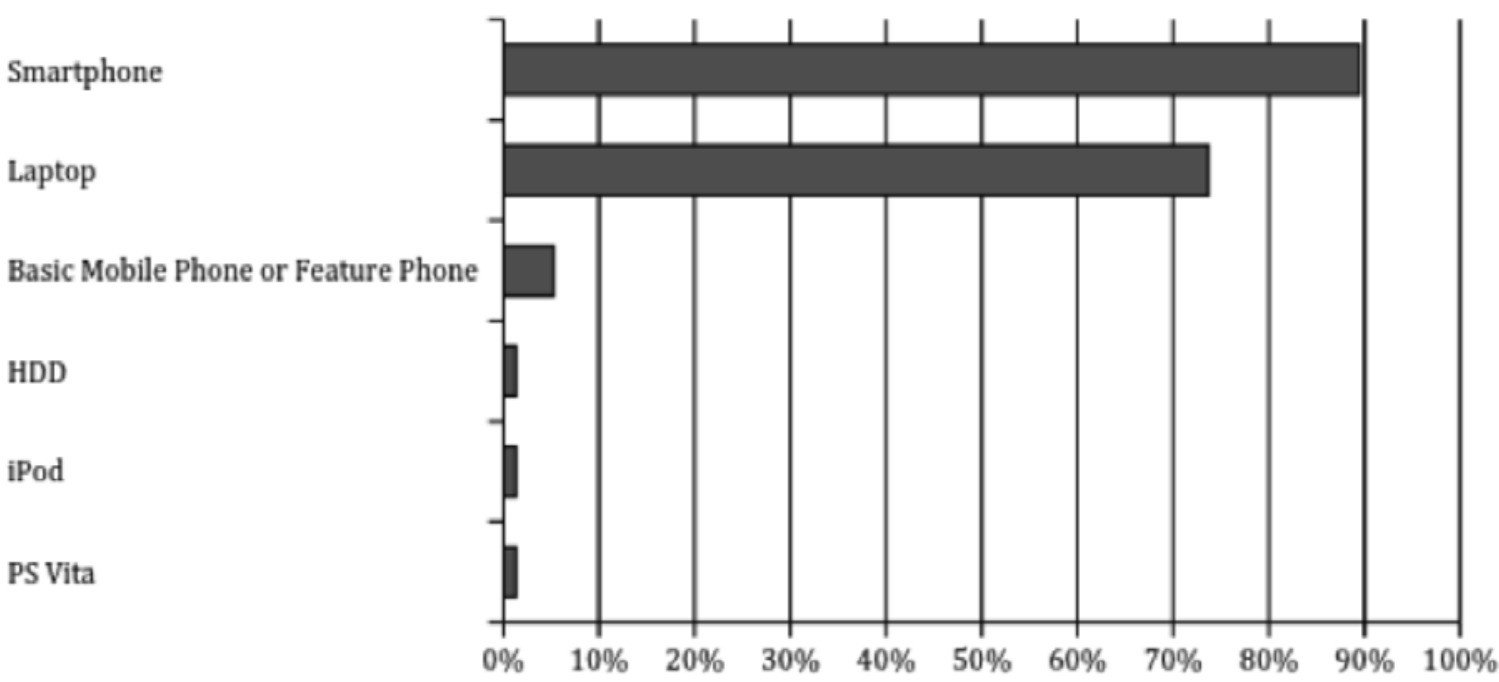

Figure 5. Other technology non-tablet owners brought to university

\section{Interview results}

The super users focused on the relevant functionality and specific apps that they used for their studies whilst by contrast the non-tablet owners were not as forthcoming with their opinions during the interview process. 
Responses from our interviews of tablet-owning students offered up several key themes in terms of why the devices are particularly suited to their studies, primarily tablet mobility and flexibility. It must, however, first be noted that these students were not using only tablet devices in the educational context.

Instead, we found that all of the interviewees owned other devices, such as mobile phones and laptops, and moved between them based on the type of task. For example, one student commented, "I do most of my work on my laptop not the desktop that I'm given ... I tend to keep social stuff on my phone ... and my work e-mail funny enough I will check on my laptop." Yet another commented that "I usually use the laptop, but sometimes I use my desktop computer, depending on what I'm doing", and another commented, "I don't have a lot of videos and stuff - I keep the music on the other one." Saying that, our interviewees stated that tablets were uniquely placed as they overlapped the functionality offered by other devices; "I think they're brilliant in terms of what they can do ... the tablet sort of sits across the areas [of smartphone and laptop].” Tablet devices were certainly seen as functional devices in this sphere, as one interviewee commented:

There's only a couple of things where you go, that's not worth trying to tackle on the iPad, usually serious spreadsheets or serious documents ... So, any kind of serious presentation graphics or serious documents, serious spreadsheets, I wouldn't use the iPad, but pretty much everything else. It's a serious enough platform that you can do serious work if you want to.

The flexibility of tablet devices was further enhanced by the plethora of applications available, with one interviewee stating that "the device is what you make of it because it's your choice of what apps you download and what apps you use or how you customise that experience yourself."

Further, our interviewees noted that tablet devices can be easily supplemented with accessories and their usefulness is not limited to the inbuilt hardware. One of our interviewees reported using a stylus to assist in her drawing and design work, whilst another owned a keyboard and preferred to type notes to provide an easy, searchable reference point. Whether it is a separate keyboard for typing or a stylus to assist with drawing, these accessories enable students to enhance the tablet's hardware as they find necessary.

The portability and battery life offered by tablets was particularly notable to our interviewees. Generally, tablets weigh far less than most laptops: "There's a key point, I think with mobility - laptops are quite heavy." In addition, tablets have at least equivalent battery life: "It's easy to carry, fashionable, and it has a longer battery life than my laptop.”

One underlying theme was that interviewees who owned tablets perceived them as trendy: "Easy to carry, fashionable, accessories that are also fashionable".

Apart from the difficulties in using their tablets for serious tasks, such as the spreadsheets and documents mentioned above, tablet-owning interviewees reported no problems with using their tablets for their studies, either on or off campus. Further, none of these students reported any difficulty with connecting to the university's network or using the university's IT systems.

When asked if they thought there was a place for tablets in their classes, all of the interviewees, both super users and non-tablet owners, responded positively. One respondent offered the following: "When I look around a classroom everyone is looking at their lecture notes on the tablet, so why not use them more?" Whilst another stated: "I think, depending on what type of learner you are, some students probably find it a lot more helpful.” However, there were differing views as to whether they should be mandatory: "I'm not sure I would buy one just because I was told to by a university or lecturer; it is a lot of money."

The main theme found in interviews of students who did not own a tablet was that whilst they were interested in tablet devices, they did not see an immediate need to purchase the devices. One of the unique responses of non-tablet owners was that they felt that tablets were not as versatile and they preferred other devices: "I like the idea of tablets, but I just feel like they don't give me anything that my computer and phone don't. They just seem like a good tool for procrastinating really.” 


\section{Discussion}

\section{Students' tablet ownership}

The results from our survey indicate that tablet ownership amongst students seems to be consistent with the increasing popularity of the devices in the greater population, and in fact that students have adopted the devices in greater numbers than general population surveys suggest. Certainly, the percentage of students surveyed who owned tablets (62\%) is greater than the percentage of tablet ownership reported in Australia; the Telsyte (2014) Australian media tablet study found that $40 \%$ of the Australian population owned tablets. The figures reported by this survey also represent a large increase from the 2012 Pearson technology survey of students, which found that $25 \%$ of students owned tablets. Our interview subjects certainly agreed that many of their peers appeared to own and use tablets for their studies; one commenting the following: "I think lots of students have tablets ... when I look around a classroom everyone is looking at their lecture notes on the tablet.” Importantly, our research indicates that it appears that the devices have certainly made their mark on the student population, with more of our respondents owning tablets than not.

These figures are additionally important to educators; it is not only that students own the devices, but they are bringing them to university as well. In fact, $50 \%$ of students surveyed indicated that they frequently or always bring their tablets to class, and a further $25 \%$ of students sometimes bring them; this means that it is likely that almost every other student will have a tablet with them in class (Table 2).

This is more than enough, in a collaborative learning environment, for all students in a classroom to have access to a tablet without any additional devices being provided by the institution. The advantages of integrating tablets into university pedagogies, much discussed in previous research, need not imply widespread university-sponsored adoption programs, but are in fact possible with the current numbers of tablets already owned by students.

Our study has found that students believe tablet devices can be useful to their studies; in fact only a third of students who owned tablets did not consider their educational uses in their decision to purchase their current device (Table 3). This ties in with previous research (Guhr \& Gair, 2013) indicating that students feel that the technology has obvious relevance to their education.

Whilst we also found that the students were more likely to own Apple tablets than other models, this is not particularly surprising. Whilst in the 12-month period to the end of 2014 Android tablets sales have overtaken those of Apple iPads (Gartner, 2014), this has not yet impacted significantly on the student populace. Further, our super user interviewees all indicated that they were early adopters of the technology, purchasing their tablets whilst Apple still had the majority of the market. Further research in this area may be useful as Apple's competitors make further inroads into this market, to indicate whether this factor is due to Apple's early dominance, or whether this brand has a particular appeal to the student market.

\section{Current student usage of tablets}

One of the aims of this study was to determine what students currently use their tablets for, both in terms of their studies and otherwise. It is clear that students are using their tablets in a variety of ways. Similar to findings by Gosper, Malfroy, and McKenzie (2013), we found that the most popular uses that students made of their tablets in relation to their studies were traditional, the most popular being email and Internet usage, and centred around the basic capabilities and connectedness offered by the devices. Many students reported that they used their tablets to access course documents, which is unsurprising as the university currently uses the Blackboard Learn ${ }^{\mathrm{TM}}$ platform (available for tablets and smartphones as Blackboard Mobile Learn ${ }^{\mathrm{TM}}$ ) as the main way to distribute course documents. The platform's mobile accessibility seems to have been embraced by tablet-owning students as $62.9 \%$ of students surveyed used their tablets for this purpose (Figure 3). More than half of students surveyed also reported that they used their tablets to read required texts, and it is clear from our interview responses that this could be further taken advantage of by the university. This would further encourage students to embrace the devices, as indicated by following response;: "I’d consider getting one if my textbooks were all available in e- 
textbook form or something like that. My high school does that.” Aside from required texts, our interviewees also noted that tablets worked together with digital library access to assist them in their studies; whilst one interviewee commented that "a lot of the time the reason why I use [the tablet] is because the article or the document is free ... the [university] library has eReader editions you can download and have access to, that as academic books would cost loads of money." Another continued, "The fact that that's all accessible through the iPad, or anywhere really, means I don't have to be [on campus].”

Interestingly, whilst social media was used by over three quarters of students outside their studies, only half of students reported that they used this for their studies (Figures 3 and 4), perhaps indicating that this area could be expanded in the university context. We also found that very few students were currently using their tablets for less traditional content-creation purposes (Figure 3), with fewer than 30\% of students reporting these methods in relation to their studies. This is in contrast with more than $40 \%$ of students taking photos and slightly more than $20 \%$ recording video outside of their studies.

In the context of the classroom or lecture theatre, we found that $66.13 \%$ of students surveyed indicated that they used their tablets to either follow along or take notes on lectures. From the responses to our interviews, it is clear that tablets were particularly suited to this task. Whether this is typing lectures, or following along with the PDF lecture slides provided through Blackboard Learn ${ }^{\mathrm{TM}}$, or annotating these PDFs, students can see the obvious advantage of the technology. One student commented, "You can pull up the lecture notes ... I couldn't understand why anyone was there actually taking notes down on a pad!”; another had the following comment to offer: "At the moment, usually I print out my lectures notes and bring them with me into lectures but if I had a tablet I would probably just bring in the tablet." The particular advantage of tablet devices in this area is that, whilst students can type notes up the same way they might on a laptop, the touchscreen of a tablet also offers a more traditional writing approach: "I see people taking notes in lectures on their iPads and it does seem a lot easier for them to hand-write them out ... depending on what type of learner you are, some students probably find it helpful.” This shows that students are not waiting for lecturers to integrate tablets into the classrooms but instead are taking the lead. This correlates with student expectations as noted by Guhr and Gair, (2013). Thus, students are exploiting the aforementioned multimedia and note-taking capabilities present in these devices (Hahn \& Bussell, 2012).

The traditional roles of the student and teacher are being challenged as proposed, by Manuguerra and Petocz (2011). Certainly the super users interviewed were extremely proactive in searching out apps and making decisions about how they used tablets in their studies. This provides some tentative evidence for students taking greater responsibility in their learning.

\section{Conclusion}

The wide use of tablets at the university studied is definitely evident, as it is across the more general population. From our review of the literature, there appear to be very few negatives to embracing this technology in universities, whilst positives include an increase in student engagement and collaborative learning. Our study of 200 undergraduate and postgraduate students, across a range of disciplines, has found that the devices are already in the hands of more than half of the students; they are using them for their studies and bringing them to university. As such, integrating tablets into teaching approaches is not out of the realms of possibility. Universities could encourage collaborative learning environments by which students share their own tablets. In this way universities do not need to actively provide the devices to students. Certainly, universities should not make the devices mandatory; any such added cost to students would need to be offset by assistance schemes. However, it seems that tablet uptake by students could be easily encouraged by providing more digital resources viewable on tablets, such as textbooks in digital format, and online course material.

However, students seem to want, and have already embraced, an environment that is supportive of a bring your own device (BYOD) strategy. This allows students to choose how they wish to participate and which device they purchase and bring to university. After all, most functions available on a tablet are also possible on laptops and smartphones. As such, we do not recommend that universities undertake expensive programs to provide students with tablet devices or implement pedagogies that necessitate 
individual students having access to these devices at this time; however, this may need to be re-evaluated as students who are using tablet devices in primary and secondary education and view them as a regular part of education move into universities.

This study was limited in so far as the students surveyed included insufficient numbers of students from individual non-IT disciplines to complete meaningful analysis relating to their specific disciplines, for example, whether the devices were used for design or content creation purposes by those in related faculties. This study was also limited as it included students from a single university. However, whilst this study was relatively small, it shows that students are increasingly purchasing the devices, and using them in a range of ways in the current educational environment.

Our research supports conclusions that students expect tablets to be part of their education and are proactively integrating them into their studies. However, it is not clear that universities are changing their pedagogies in order for students to gain any further benefit from these devices, other than facilitating students to download e-learning materials such as lecture notes and e-books for student annotation. The study indicates that academics could make better use of learning activities involving content creation, for example, taking photos and videos, and design activities such as sketching and drawing, and use shared tablets in collaborative pedagogies.

This research contributes to our knowledge of how many of the devices are in the hands of students and provides a baseline to educators. Furthermore, it provides a rich picture of how students are currently using their tablets both in their studies and outside of the educational setting, and this understanding should assist academics to incorporate the technology effectively in new learning activities into the future.

This study opens up many avenues for worthwhile research. Further research into the differences relating to tablet brands may provide interesting insights as the tablet market continues to fragment. This information would be useful for institutions contemplating the purchase of tablets for their students. In addition to this, we suggest research regarding students' use of multiple devices for their studies, such as smartphones, laptops, and tablets, and the relative merits of these for different tasks. A comparison with students' mobile technology use outside university would also be interesting. Finally, we believe that a comparative study of students' tablet usage at universities that have implemented programs to provide tablet devices and universities that have not, would be of particular interest in ascertaining the future value of these devices in the educational sphere.

\section{References}

Amelink, C. T., Scales, G., \& Tront, J. G. (2012). Student use of the tablet PC: Impact on student learning behaviors. Advances in Engineering Education, 1-17. Retrieved from http://aee.asee.org/wpcontent/uploads/vol03/issue01/papers/aee-vol03-issue01-p04.pdf

AppBrain. (2015). Stats. Retrieved October 20, 2015, from http://www.appbrain.com/stats/androidmarket-app-categories

Apple Inc. (2010, January 27). Apple launches iPad: Magical \& revolutionary device at an unbelievable price. Apple Press Info. Retrieved from http://www.apple.com/pr/library/2010/01/27Apple-LaunchesiPad.html

Apple Inc. (2015a). iPad helps University of Adelaide transform its science curriculum. Real Stories. Retrieved from http://www.apple.com/au/education/profiles/adelaide/\%3E

Apple, Inc. (2015b). iPad in education: App store - whatever the lesson, make apps part of the plan. Retrieved from http://www.apple.com/au/education/ipad/apps-books-and-more/

Churchill, D., Fox, B., \& King, M. (2012). Study of affordances of iPads and teachers' private theories. International Journal of Information and Education Technology, 2(3), 251-254. doi:10.7763/IJIET.2012.V2.122

Claburn, T. (2012. October 25). iPad university: IT lessons from college pilot. Information Week. Retrieved from http://www.informationweek.com/mobile/mobile-devices/ipad-university-it-lessonsfrom-college-pilot/d/d-id/1107059?

Gartner Inc. (2014, March 3). Gartner says worldwide tablet sales grew 68 percent in 2013, with Android capturing 62 percent of the market (Press release). Retrieved from

http://www.gartner.com/newsroom/id/2674215 
Google. (2014). Educational App Store. Retrieved from https://web.archive.org/web/20140601074439/https://play.google.com/store/apps/details?id=education alappstore.eas\&hl=en

Gosper, M., Malfroy, J., \& McKenzie, J. (2013). Students’ experiences and expectations of technologies: An Australian study designed to inform planning and development decisions, Australasian Journal of Educational Technology, 29(2), 268-282. Retrieved from http://ajet.org.au/index.php/AJET/article/view/127

Guhr, D., \& Gair, G. (2013). The impact of the rapidly changing mobile devices market on e-Learning in higher education. Journal of Systemics, Cybernetics and Informatics, 11(7), 28-31. Retrieved from http://www.iiisci.org/journal/sci/FullText.asp?var=\&id=iHB193DJ

Hahn, J., \& Bussell, H. (2012). Curricular use of the iPad 2 by a first-year undergraduate learning community. Library Technology Reports, 48(8), 42-7.

Hargis, J., Cavanaugh, C., Kamali, T., \& Soto, M. (2013). A federal higher education iPad mobile learning initiative: Triangulation of data to determine early effectiveness. Innovative Higher Education, 1-13. doi:10.1007/s10755-013-9259-y

Hood, A. (2014, February 10). 5 ways universities can capitalize on mobile [Blog post]. Phase 2. Retrieved from http://www.phase2technology.com/blog/5-ways-universities-can-capitalize-on-mobile/ Johal, N. (2012). Beyond paper: Can digital textbooks transform higher education? London: OVUM.

Johnson, L., Adams, S., \& Cummins, M. (2012). NMC Horizon Report: 2012 Higher Education Edition. Austin, TX: New Media Consortium.

Manuguerra, M., \& Petocz, P. (2011). Promoting student engagement by integrating new technology into tertiary education: The role of the iPad. Asian Social Science, 7(11), 61-5. doi:10.5539/ass.v7n11p61

Pearson Foundation. (2012). Pearson Foundation survey on students and tablets. New York, NY: Author. Retrieved from http://online.annamaria.edu/sites/amc/files/PF_Tablet_Survey_Summary_2012.pdf

Telsyte. (2014, March 18). Australian media tablet sales double in 2013 as low cost units flood the market (Media release). Retrieved from https://www.whatech.com/consumer-electronics/pressrelease/19184-australian-media-tablet-sales-double-in-2013-as-low-cost-units-flood-the-market

Van Oostveen, R, Muirhead, W., \& Goodman, W.M. (2011). Tablet PCs and reconceptualizing learning with technology: A case study in higher education. Interactive Technology and Smart Education, 8(2), 78-93. doi:10.1108/17415651111141803

Wakefield, J., \& Smith, D. (2012). From Socrates to satellites: iPad learning in an undergraduate course. Creative Education, 3, 643-648. doi:10.4236/ce.2012.35094

Corresponding author: David Green, dbmgreen@me.com

Australasian Journal of Educational Technology (c) 2016.

Please cite as: Green, D., Naidoo, E., Olminkhof, C., \& Dyson, L.E. (2016). Tablets@university: The ownership and use of tablet devices by students. Australasian Journal of Educational Technology, 32(3), 50-64. 